\title{
Relationships between cardiovascular signs and neurological signs in asphyxiated neonates in Ilorin, North Central Nigeria
}

\author{
Amudalat Issa ${ }^{1}$, Mohammed Baba Abdulkadir ${ }^{2,3}$, Omotayo Olukemi Adesiyun ${ }^{2,3}$, \\ Bilkis Owolabi ${ }^{4}$, Habibat Suberu², Kayode Olusegun Alabi², Ruqayat Ronke Bakare ${ }^{2}$
}

1. Children Specialist hospital, Ilorin, Nigeria.

2. Department of Paediatrics and Child Health, University of Ilorin Teaching Hospital,

3. Department of Paediatrics and Child Health, University of Ilorin, Nigeria.

4. General hospital, Ilorin, Nigeria.

\section{Author emails:}

Mohammed B. Abdulkadir: docmohng@gmail.com, +2348065754333; OO Adesiyun: omotayoadesiyun@yahoo.com; BI Owolabi: owolabibilly@yahoo.com, 08036139545; Suberu DH: queenbeeba6@gmail.com,08034410523; Alabi KO: drkayodealabi1@gmail.com, 08060223572; Bakare RR: straight2bak@gmail.com, 08057432625.

\begin{abstract}
Background: Perinatal asphyxia is a condition associated with multiple organ dysfunctions inclusive of cardiovascular dysfunction. Neurologic predictors of survival have been studied, but little has been reported regarding cardiovascular signs and their role in determining outcome in asphyxia.

Objective: The study aimed to determine the relationship between cardiovascular signs and outcomes in asphyxiated newborns with hypoxic ischaemic encephalopathy.

Methods: This was a cross sectional study involving asphyxiated new-born babies recruited within the first 24 hours of life. Hypoxic ischaemic encephalopathy staging was done using Sarnat and Sarnat staging. All patients had a detailed cardiovascular examination on admission, after initial resuscitation (30-60 minutes) into admission, and were followed till final outcome: discharge or death.

Results: Eighty-five asphyxiated new-borns with HIE were studied over seven months. Abnormal cardiovascular-related signs identified in the patients included respiratory distress (64.7\%), small volume pulse (57.6\%), hypotension (52.9\%), hypoxemia $(48.2 \%)$ and shock $(32.9 \%)$. Five babies died. None of the clinical signs had a significant relationship with mortality. Conclusion: Abnormal cardiovascular signs increased with the progression of HIE staging but had no relationship with mortality.

Keywords: Cardiovascular signs, Neurological outcomes, Mortality, Perinatal asphyxia.

DOI: https://dx.doi.org/10.4314/ahs.v21i2.33

Cite as: Issa A, Abdulkadir MB, Adesiyun OO, Owolabi B, Suberu H, Alabi KO, et al. Relationships between cardiovascular signs and neurological signs in asphyxiated neonates in Ilorin, North Central Nigeria. Afri Health Sci. 2021;21(2). 743-752. bttps:/ / dx.doi.org/10.4314/abs.v21i2.33
\end{abstract}

\section{Introduction}

Perinatal asphyxia is defined as progressive hypoxaemia

\author{
Corresponding author: \\ Amudalat Issa, \\ Consultant Paediatric cardiologist, \\ Children Specialist Hospital, \\ Ilorin Kwara State, \\ 08064361650.
}

Email: issahamdallah27@gmail.com and hypercarbia accompanied by the progressive development of metabolic acidosis.1 It occurs during the perinatal period as a result of compromised placental or pulmonary gas exchange. ${ }^{1}$ It manifests in multiple organs, including the brain, kidneys, the heart and the intestines. ${ }^{1}$ Perinatal asphyxia is associated with insufficient oxygen supply to the cell and redistribution of cardiac output so as to preserve perfusion of the vital organs which include the brain, the heart, and the adrenals. ${ }^{2}$ The peripheral tissues, lungs, intestines, kid- 
neys and other organs are hypo-perfused, in order to favour the vital organs. ${ }^{3}$ However, when the hypoxic ischaemic process becomes severe and prolonged, the vital organs are also affected. ${ }^{4}$ Hypoxic ischaemic encephalopathy (HIE) is the term commonly used to describe the neurological syndrome that occurs following severe perinatal asphyxia. ${ }^{1}$ Hypoxic ischaemic encephalopathy represents the more severe end of the spectrum of organ affection in perinatal asphyxia, with central nervous system (CNS) complications manifesting later on in life as seizure disorders, cerebral palsy and mental retardation. ${ }^{6}$

Perinatal asphyxia is a common neonatal problem that contributes significantly to morbidity and mortality occurring in 1.5/1000 live births in high income countries. ${ }^{5}$ Higher incidences are generally reported in low income countries. ${ }^{6}$ In Nigeria, West and Opara ${ }^{7}$, in a study of 630 neonates admitted over a nine-month period into a Special Care Baby Unit in Port Harcourt reported the incidence of perinatal asphyxia as $24.9 \% .^{7}$ A number of studies have been conducted on complications following perinatal asphyxia, especially neurological complications. ${ }^{8}$ Less studied is the cardiac injury as part of the asphyxia syndrome, with a reported incidence of $22.5 \%$ to $73.3 \%$ in some studies. ${ }^{9,10} \mathrm{Few}$ studies have described abnormal cardiovascular signs and their relationship with survival in new-borns with hypoxic ischaemic encephalopathy especially in low income countries where they may be the only pointer to myocardial dysfunction. Thus, the present study was conducted to evaluate cardiac dysfunction in perinatal asphyxia using cardiovascular signs. The study also sought to determine the effect of cardiac dysfunction on mortality.

\section{Material and methods}

This was a cross sectional study in the neonatal unit of the University of Ilorin Teaching Hospital between January and July 2017. The hospital new-born unit serves as a referral centre for patients from neighbouring states. The Neonatal Intensive Care Unit (NICU) monthly admission range between 100 to 150 babies. Perinatal asphyxia among term babies accounts for 10 to $15 \%$ of the total admissions. The NICU has facilities for oxygen delivery, ventilatory support (continuous positive airway pressure), non-invasive monitoring, radiant warmers, incubators, phototherapy units and a functioning side laboratory.
A sample size of 85 was calculated using the Kish Leslie formula and prevalence of cardiovascular signs in asphyxiated babies as $73.3 \% .^{10}$ Ethical clearance was obtained from the Hospital Ethics Review Committee. Written informed consent was obtained from parents after a detailed explanation of the study.

Inclusion criteria were term AGA neonates with at least stage I HIE, with or without 5th minute Apgar score $\leq 6$ admitted within 24 hours of life. The diagnosis of HIE was based on Sarnat and Sarnat staging and the highest stage was assigned. ${ }^{11}$ Babies with congenital heart disease, major congenital anomalies, risk for sepsis, neonatal sepsis, maternal use of medication such as diazepam, opioids within 24 hours of delivery were excluded from the study.

All the babies had their anthropometric parameters measured and were classified based on gestational age using the Lubchenco chart. ${ }^{12}$ Relevant clinical data were obtained. All recruited babies had a detailed cardiovascular system examination recorded at admission after initial resuscitation. The recruitment was done by two of the researchers, who were senior registrars in the department of paediatrics. The blood pressure was measured in the supine position with the neonate quiet or asleep using a non-invasive oscillometric method (WelchAllyn ${ }^{\circledR}$ sphygmomanometer). An appropriate size blood pressure (BP) cuff was used. ${ }^{13}$ The BP cuff was applied to the right upper arm at the level of the right atrium. Two values of the systolic, diastolic and mean arterial blood pressures were read from the monitor and an average recorded. The values were interpreted using the normative oscillometric BP standard for African neonates by Sadoh and Ibhanesebhor. ${ }^{14}$ Values between the $5^{\text {th }}$ and the 95 th percentile were recorded as normal, values $<5^{\text {th }}$ percentile as hypotension and above the 95th percentile as hypertension. ${ }^{13}$ Oxygen saturation was measured after initial resuscitation, (about 30 minutes to 1 hour into admission) using a neonatal probe pulse oximeter. Respiratory rate was assessed by counting abdominal and chest movement over one minute with the babies exposed adequately. Other signs of respiratory distress were assessed. The heart rate was counted over 1 minute at the apex with the diaphragm of a stethoscope. Diagnosis of heart failure was made in the presence of tachycardia (heart rate $>160$ beats per minute, tachypnoea (respiratory rate $>60$ breaths per minute and tender hepatomegaly. ${ }^{15}$ Five of the babies with HIE III in coma, were excluded from assessment 
of tender hepatomegaly because of difficulties in assessing tenderness in unconscious patients. In addition, diagnosis of shock was made in the presence of poor perfusion (skin colour and capillary refill $>3$ seconds), small pulse volume with or without hypotension. ${ }^{16}$ The pulse volume was assessed by palpation of the brachial pulse using the pulp of the index and middle fingers. The pulse volume was graded as small or normal.

Data obtained was entered into a computer and analyzed using Statistical Package for Social Sciences (SPSS) software version 20.0 for Windows (SPSS Inc., Chicago, IL, USA). Frequency and mean of categorical and continuous variables were generated respectively. The Chi-square test was used to document relationship between categorical variables. Other statistical tests were used as appropriate. A p value of less than 0.05 was considered statistically significant.

\section{Results}

\section{General characteristics of the study population}

Eighty five asphyxiated neonates (AGA) with hypoxic-ischaemic encephalopathy were recruited for seven months. Twenty-three $(27.0 \%)$ had HIE stage I, 52 $(61.2 \%)$ had HIE stage II and 10 (11.8\%) had HIE stage III. The median (IQR) age at admission was 1.5 (0.5 to 6.0) hours. The study participants comprised 51
$(60.0 \%)$ males. The mean \pm SD gestational age was 39.5 \pm 1.49 weeks), birth weight $3.0 \pm 0.3$ (kg), occipitofrontal circumference $34.7 \pm 1.4(\mathrm{~cm})$, and length 49.0 $\pm 3.2(\mathrm{~cm})$.

\section{Cardiovascular examination findings}

The common abnormal cardiovascular findings were respiratory distress in $55(64.7 \%)$, small volume pulse in $49(57.6 \%)$, hypotension in $45(52.9 \%)$, low oxygen saturation (hypoxemia) in $41(48.2 \%)$, reduced peripheral perfusion in $39(45.9 \%)$ and shock in $28(32.9 \%)$. The least common were cardiac murmur [8 (9.4\%)], heart failure $[5(5.9 \%)]$ and hypertension $[1(1.2 \%)]$ as shown in Table 1.

\section{Comparison of cardiovascular signs across disease severity categories}

There was an increasing proportion of abnormal cardiovascular signs from HIE I through HIE II and HIE III. Global chi square demonstrated a significant difference in peripheral perfusion, oxygen saturation, pulse volume, pulse rhythm, presence of shock and heart failure, (each $\mathrm{p}<0.05$ ), across the three categories (Table 2). Further analysis of the group with HIE I against HIE II and III combined demonstrated peripheral perfusion, pulse volume and shock to be significantly different across the groups, Table 3. 
Table 1: Cardiovascular examination findings in the subjects

\begin{tabular}{|c|c|c|}
\hline Variable & Frequency (n) & Percentage (\%) \\
\hline \multicolumn{3}{|c|}{ Peripheral perfusion } \\
\hline Normal & 44 & 51.8 \\
\hline Reduced & 41 & 48.2 \\
\hline \multicolumn{3}{|l|}{ Central cyanosis } \\
\hline Yes & 12 & 14.1 \\
\hline No & 73 & 85.9 \\
\hline \multicolumn{3}{|l|}{$\mathrm{SPO}_{2}(\%)$} \\
\hline$\leq 94$ & 41 & 48.2 \\
\hline $95-100$ & 44 & 51.8 \\
\hline \multicolumn{3}{|c|}{ Respiratory rate (breaths/min) } \\
\hline$<30$ & 1 & 1.2 \\
\hline $30-60$ & 34 & 40.0 \\
\hline$>60$ & 50 & 58.8 \\
\hline \multicolumn{3}{|c|}{ Respiratory distress } \\
\hline Yes & 55 & 64.7 \\
\hline No & 30 & 35.3 \\
\hline \multicolumn{3}{|l|}{ Pulse volume } \\
\hline Normal volume & 36 & 42.4 \\
\hline Small volume & 49 & 57.6 \\
\hline \multicolumn{3}{|c|}{ Heart rate (beats/min) } \\
\hline$<120$ & 5 & 5.9 \\
\hline $120-160$ & 65 & 76.5 \\
\hline$>160$ & 15 & 17.6 \\
\hline \multicolumn{3}{|l|}{ Blood pressure } \\
\hline Hypotension & 45 & 52.9 \\
\hline Normal & 39 & 45.9 \\
\hline Hypertension & 1 & 1.2 \\
\hline \multicolumn{3}{|l|}{ Shock } \\
\hline Yes & 28 & 32.9 \\
\hline No & 57 & 67.1 \\
\hline \multicolumn{3}{|l|}{ Murmur } \\
\hline Yes & 8 & 9.4 \\
\hline No & 77 & 90.6 \\
\hline \multicolumn{3}{|c|}{ Tender hepatomegaly } \\
\hline Yes & 5 & 6.3 \\
\hline No & 75 & 93.8 \\
\hline \multicolumn{3}{|l|}{ Heart failure } \\
\hline Yes & 5 & 6.3 \\
\hline No & 75 & 93.8 \\
\hline
\end{tabular}


Table 2: Comparison of cardiovascular signs across disease severity categories

\begin{tabular}{|c|c|c|c|c|c|c|}
\hline $\begin{array}{l}\text { Variable } \\
\mathrm{N}=85\end{array}$ & $\begin{array}{c}\text { HIE I } \\
n=23 \\
n(\%) \\
\end{array}$ & $\begin{array}{c}\text { HIE II } \\
n=52 \\
n(\%) \\
\end{array}$ & $\begin{array}{c}\text { HIE III } \\
n=10 \\
n(\%) \\
\end{array}$ & $\begin{array}{c}\text { Total } \\
\mathbf{N}\end{array}$ & $\overline{\chi^{2}}$ & $p$ value \\
\hline \multicolumn{7}{|c|}{ Peripheral perfusion } \\
\hline Normal & $17(73.9)^{\mathrm{a}}$ & $26(50.0)^{\mathrm{a}}$ & $1(10.0)^{\mathrm{b}}$ & 44 & 11.569 & 0.003 \\
\hline Reduced & $6(26.1)$ & $26(50.0)$ & $9(90.0)$ & 41 & & \\
\hline \multicolumn{7}{|l|}{ Central cyanosis } \\
\hline Yes & $1(4.3)^{\mathrm{a}}$ & $7(13.5)^{\mathrm{ab}}$ & $4(40.0)^{\mathrm{b}}$ & 12 & $4.695^{\mathrm{y}}$ & 0.096 \\
\hline No & $22(95.7)$ & $45(86.5)$ & $6(60.0)$ & 73 & & \\
\hline \multicolumn{7}{|l|}{$\mathrm{SPO}_{2}(\%)$} \\
\hline$<94$ & $8(34.8)^{a}$ & $23(44.2)^{\mathrm{a}}$ & $10(100.0)^{\mathrm{b}}$ & 41 & 12.733 & 0.002 \\
\hline $94-100$ & $15(65.2)$ & $29(55.8)$ & $0(0.0)$ & 44 & & \\
\hline \multicolumn{7}{|l|}{ (breaths/min) } \\
\hline$<30$ & $0(0.0)^{\mathrm{a}}$ & $0(0.0)^{\mathrm{a}}$ & $1(10.0)^{\mathrm{a}}$ & 1 & $0.374^{\mathrm{r}}$ & 0.985 \\
\hline $30-60$ & $8(34.8)$ & $22(42.3)$ & $4(40.0)$ & 34 & & \\
\hline$>60$ & $15(65.2)$ & $30(57.7)$ & $5(50.0)$ & 50 & & \\
\hline \multicolumn{7}{|c|}{ Respiratory distress } \\
\hline Yes & $14(60.9)^{\mathrm{a}}$ & $33(63.5)^{\mathrm{a}}$ & $8(80.0)^{\mathrm{a}}$ & 55 & 1.208 & 0.547 \\
\hline No & $9(39.1)$ & $19(36.5)$ & $2(20.0)$ & 30 & & \\
\hline \multicolumn{7}{|l|}{ Pulse volume } \\
\hline Full volume & $18(78.3)^{\mathrm{a}}$ & $17(32.7)^{\mathrm{b}}$ & $1(10.0)^{\mathrm{b}}$ & 36 & 18.421 & $<0.001$ \\
\hline Small volume & $5(21.7)$ & $35(67.3)$ & $9(90.0)$ & 49 & & \\
\hline \multicolumn{7}{|c|}{ Heart rate (beats/minute) } \\
\hline$<120$ & $0(0.0)^{\mathrm{a}}$ & $2(3.8)^{\mathrm{a}}$ & $3(30.0)^{\mathrm{a}}$ & 5 & $7.138^{\mathrm{y}}$ & 0.129 \\
\hline $120-160$ & $18(78.3)$ & 41 (78.9) & $6(60.0)$ & 65 & & \\
\hline$>160$ & $5(21.7)$ & $9(17.3)$ & $1(10.0)$ & 15 & & \\
\hline \multicolumn{7}{|l|}{ Blood pressure } \\
\hline Hypotension & $12(52.2)^{\mathrm{a}}$ & $27(51.9)^{\mathrm{a}}$ & $6(60.0)^{\mathrm{a}}$ & 45 & $1.750^{\mathrm{Y}}$ & 0.782 \\
\hline Normal & $11(47.8)$ & $25(48.1)$ & $3(30.0)$ & 39 & & \\
\hline Hypertension & $0(0.0)$ & $0(0.0)$ & $1(10.0)$ & 1 & & \\
\hline \multicolumn{7}{|l|}{ Shock } \\
\hline Yes & $1(4.3)^{\mathrm{a}}$ & $20(38.5)^{b}$ & $7(70.0)^{\mathrm{b}}$ & 28 & 15.447 & $<0.001$ \\
\hline No & $22(95.7)$ & $32(61.6)$ & $3(30.0)$ & 57 & & \\
\hline \multicolumn{7}{|l|}{ Murmur } \\
\hline Yes & $1(4.3)^{\mathrm{a}}$ & $6(11.5)^{\mathrm{a}}$ & $1(12.5)^{\mathrm{a}}$ & 8 & $0.536^{\mathrm{Y}}$ & 0.765 \\
\hline No & $22(95.7)$ & $46(88.5)$ & $9(11.7)$ & 77 & & \\
\hline \multicolumn{7}{|l|}{ Heart failure } \\
\hline Yes & $0(0.0)^{\mathrm{a}}$ & $2(3.8)^{\mathrm{ab}}$ & $3(60.0)^{\mathrm{b}}$ & 5 & $26.699^{\mathrm{x}}$ & $<0.001$ \\
\hline No & $\begin{array}{c}23 \\
(100.0)\end{array}$ & $50(96.2)$ & $2(40.0)$ & 75 & & \\
\hline
\end{tabular}


Table 3: Comparison of cardiovascular signs across disease severity categories HIE I against HIE II and III

\begin{tabular}{|c|c|c|c|c|c|}
\hline $\begin{array}{l}\text { Variable } \\
\mathrm{N}=85\end{array}$ & $\begin{array}{c}\text { HIE I } \\
\text { n=23 } \\
\text { n (\%) }\end{array}$ & $\begin{array}{c}\text { HIE II \& III } \\
\text { n=62 } \\
\text { n }(\%)\end{array}$ & $\begin{array}{c}\text { Total } \\
\mathbf{N}=85\end{array}$ & $\chi^{2}$ & $p$ value \\
\hline \multicolumn{6}{|c|}{ Peripheral perfusion } \\
\hline Normal & $17(38.6)$ & $27(61.3)$ & 44 & 6.195 & 0.013 \\
\hline Reduced & $6(17.1)$ & $35(85.4)$ & 41 & & \\
\hline \multicolumn{6}{|l|}{ Central cyanosis } \\
\hline Yes & $1(8.3)$ & $11(91.7)$ & 12 & 2.482 & 0.115 \\
\hline No & $22(30.1)$ & $51(7.0)$ & 73 & & \\
\hline \multicolumn{6}{|l|}{$\mathrm{SPO}_{2}(\%)$} \\
\hline$<94$ & $8(19.5)$ & $33(80.4)$ & 41 & 2.285 & 0.131 \\
\hline $94-100$ & $15(34.1)$ & $29(65.9)$ & 44 & & \\
\hline \multicolumn{6}{|c|}{ Respiratory rate (breaths/min) } \\
\hline$<30$ & $0(0.0)$ & $1(100.0)$ & 1 & 0.805 & 0.669 \\
\hline $30-60$ & $8(23.5)$ & $26(76.5)$ & 34 & & \\
\hline$>60$ & $15(30.0)$ & $35(70.0)$ & 50 & & \\
\hline \multicolumn{6}{|c|}{ Respiratory distress } \\
\hline Yes & $14(25.5)$ & $41(74.5)$ & 55 & 0.203 & 0.652 \\
\hline No & $9(30.0)$ & $21(70.0)$ & 30 & & \\
\hline \multicolumn{6}{|l|}{ Pulse volume } \\
\hline Full volume & $18(50.0)$ & $18(50.0)$ & 36 & 16.652 & $<0.001$ \\
\hline Small volume & $5(10.2)$ & $44(89.8)$ & 49 & & \\
\hline \multicolumn{6}{|c|}{ Heart rate (beats/minute) } \\
\hline$<120$ & $0(0.0)$ & $5(100.0)$ & 5 & 2.167 & 0.338 \\
\hline $120-160$ & $18(27.7)$ & $47(72.3)$ & 65 & & \\
\hline$>160$ & $5(33.3)$ & $10(66.7)$ & 15 & & \\
\hline \multicolumn{6}{|l|}{ Blood pressure } \\
\hline Normal & $11(28.2)$ & $28(71.8)$ & 39 & 0.048 & 0.827 \\
\hline Abnormal & $12(26.1)$ & 34 (73.9) & 46 & & \\
\hline \multicolumn{6}{|l|}{ Shock } \\
\hline Yes & $1(3.6))$ & $27(96.4)$ & 28 & 11.671 & 0.001 \\
\hline No & $22(38.6)$ & 35 (61.4) & 57 & & \\
\hline \multicolumn{6}{|l|}{ Murmur } \\
\hline Yes & $1(12.5)$ & $7(87.5)$ & 8 & 0.948 & 0.330 \\
\hline No & $22(28.6)$ & $55(71.4)$ & 77 & & \\
\hline \multicolumn{6}{|l|}{ Heart failure } \\
\hline Yes & $0(0.0)$ & $5(100.0)$ & 5 & 2.152 & 0.142 \\
\hline No & $23(29.3)$ & $52(69.3)$ & 75 & & \\
\hline
\end{tabular}

\section{Comparison of cardiovascular signs across HIE categories}

Table 4 shows the comparison of the cardiovascular vital signs across the disease categories. Oxygen saturation was the only parameter with significant relationship across the HIE stages. The mean respiratory rate and heart rate in the participants (all stages) were $66.0 \pm$ 18.94 breaths per minute and $146.06 \pm 15.53$ beats per minute respectively. Similarly, the systolic, diastolic and mean arterial blood pressure was $58.47 \pm 9.70,28.04 \pm$ $9.03,38.18 \pm 8.18 \mathrm{mmHg}$ respectively.

\section{Regression analysis of cardiovascular signs and} HIE severity categories

The significant cardiovascular signs in the earlier univariate analyses were subjected to multivariate logistic regression analysis with HIE categories using HIE I as reference category against HIE II and III combined. Pulse volume was the only significant cardiovascular parameter with an independent relationship (four times likelihood) among subjects with HIE II and III compared with HIE I. (Table 5) 
Table 4: Comparison of cardiovascular signs across HIE categories

\begin{tabular}{|c|c|c|c|c|c|}
\hline Variable & $\begin{array}{l}\text { HIE I } n=23 \\
\text { Mean } \pm \text { SD }\end{array}$ & $\begin{array}{l}\text { HIE II n=52 } \\
\text { Mean } \pm \text { SD }\end{array}$ & $\begin{array}{l}\text { HIE III n=10 } \\
\text { Mean } \pm \text { SD }\end{array}$ & $\boldsymbol{F}$ & $p$ \\
\hline $\begin{array}{l}\text { Respiratory rate } \\
\text { (breaths/minute) }\end{array}$ & $66.9 \pm 18.4$ & $66.8 \pm 19.2$ & $60.1 \pm 19.8$ & 0.544 & 0.582 \\
\hline SPO2 (\%) & $93.1 \pm 7.0$ & $92.5 \pm 8.6$ & $80.6 \pm 10.5$ & 9.062 & $<0.001$ \\
\hline Heart rate (beats/minute) & $149.2 \pm 13.6$ & $145.6 \pm 14.4$ & $141.2 \pm 23.8$ & 0.973 & 0.382 \\
\hline Systolic BP (mmHg) & $59.3 \pm 7.7$ & $58.8 \pm 8.7$ & $55.2 \pm 16.9$ & 0.662 & 0.519 \\
\hline Diastolic BP (mmHg) & $28.6 \pm 7.8$ & $28.3 \pm 8.4$ & $25.3 \pm 14.2$ & 0.519 & 0.597 \\
\hline Pulse pressure (mmHg) & $30.7 \pm 9.1$ & $30.4 \pm 9.4$ & $29.9 \pm 9.4$ & 0.260 & 0.975 \\
\hline $\begin{array}{l}\begin{array}{l}\text { Mean } \\
(\mathrm{mmHg})\end{array} \\
\text { arterial }\end{array}$ & $38.8 \pm 6.5$ & $38.5 \pm 7.3$ & $35.3 \pm 14.5$ & 0.728 & 0.486 \\
\hline
\end{tabular}

Table 5: Regression analysis of HIE severity categories with selected cardiovascular signs

\begin{tabular}{llllll}
\hline Variable & B & SE & OD & $(95 \%$ & Confidence \\
& & &
\end{tabular}

HIE II \& III

\begin{tabular}{|c|c|c|c|c|}
\hline $\begin{array}{l}\text { Peripheral } \\
\text { perfusion }\end{array}$ & 0.363 & 0.712 & $1.438(0.36-5.81)$ & 0.610 \\
\hline Pulse volume & 1.517 & 0.673 & $4.558(1.22-17.05)$ & 0.024 \\
\hline Shock & -1.489 & 1.331 & $0.226(0.02-3.06)$ & 0.263 \\
\hline Oxygen saturation & -.010 & 0.038 & $0.990(0.92-1.07)$ & 0.780 \\
\hline
\end{tabular}

Reference category: HIE stage I, $B$ * Regression coefficient, $O D * O d d$ ratio

Relationship between stages of HIE and mortality Five of the 85 patients with HIE died, giving a case fatality of $5.9 \%$. The case fatality was highest with stage III disease $(40.0 \%)$ and lowest with stage I $(0.0 \%)$. Hypoxic ischaemic encephalopathy stage III constituted the highest proportion of $4(80.0 \%)$ of the total mor- tality. There was a significant difference between stages of HIE and mortality, ( $p<0.001)$, Table 6.

Regression analysis of significant cardiovascular signs with mortality

Table 7 shows binary logistic regression analysis of the significant cardiovascular signs with mortality. None of the signs was a significant predictor of mortality. 
Table 6: Relationship between stages of HIE and mortality

\begin{tabular}{lcccc}
\hline Disease stage & \multicolumn{2}{c}{ Outcome at discharge } & $\boldsymbol{\chi}^{2}$ & $p$ value \\
& Survived $\mathbf{n}(\%)$ & Died $\mathbf{n}(\%)$ & & \\
\hline HIE stage I & $23(100.0)$ & $0(0.0)$ & 23.95 & $<\mathbf{0 . 0 0 1}$ \\
HIE stage II & $51(98.1)$ & $1(1.9)$ & & \\
HIE stage III & $6(60.0)$ & $4(40.0)$ & & \\
Total & $80(94.1)$ & $5(5.9)$ & & \\
\hline
\end{tabular}

HIE: hypoxic ischaemic encephalopathy

Table 7: Regression analysis of significant cardiovascular signs with mortality

\begin{tabular}{lllll}
\hline Variable & B & SE & $p$ & OD (Confidence Interval) \\
\hline Peripheral perfusion & -1.221 & 1.588 & 0.442 & $0.295(0.13-6.631)$ \\
Pulse volume & -0.727 & 1.564 & 0.642 & $0.483(0.02-10.36)$ \\
Shock & 0.131 & 1.610 & 0.935 & $1.140(0.49-26.7)$ \\
Oxygen saturation & 0.036 & 0.042 & 0.394 & $1.036(0.96-1.13)$ \\
\hline
\end{tabular}

Reference category $=$ Survival, $B^{*}$ Regression coefficient, $O D$ *odd ratio

\section{Discussion}

Oxygen homeostasis is critical for survival and function of all cells in the body including the myocardium. Hypoxia is characterized by inadequate oxygen delivery to the myocardium. ${ }^{2}$

Myocardial hypoxia/ischaemia following perinatal asphyxia may manifest by changes in the heart rate, poor peripheral perfusion, and rise in systemic and central venous pressure. As the myocardium fails, central venous pressure rises further, systemic pressure decreases, and the heart rate drops further. ${ }^{2}$ The mean respiratory rate (66.00 breaths/minute) found in asphyxiated newborn babies with HIE in the present study is similar to 68.00 breaths/minute earlier reported among asphyxiated neonates in the United States. ${ }^{17}$ Also, the mean heart rate found in the current study compares with 145 beats per minute and 146 beats per minute reported in the earlier studies. ${ }^{17,18}$

The mean systolic blood pressure (SBP) of 58.47 $\mathrm{mmHg}$ herein reported is close to $66.00 \mathrm{mmHg}$ reported by Hall et al. ${ }^{17}$ However, it is much lower than 99.10 $\mathrm{mmHg}, 76.50 \mathrm{mmHg}$, and $71.70 \mathrm{mmHg}$ reported in another study, with measurement obtained at less than 15 minutes, 15 to 30 minutes and 30 to 60 minutes of life respectively. ${ }^{19}$ It is this methodological difference from the current study, which obtained blood pressure recordings up to the sixth hour of life, that probably explains the difference in observations. It has been shown that there is a hypertensive response soon after a perinatal asphyxia event: this is followed by progressive reduction in blood pressure. ${ }^{2}$ Regarding diastolic blood pressure and mean arterial blood pressure, the mean values of 28.04 and $38.18 \mathrm{mmHg}$ in the present study are much lower than 42.00 and $49.00 \mathrm{mmHg}$ reported by Hall et $\mathrm{al}^{7}$ at less than two hours of life. ${ }^{2}$ It would be pertinent to explore possible methodological reasons for this difference but the earlier report did not indicate the method of blood pressure measurement. This is important since significant differences in diastolic blood pressure have been reported between oscillometric and auscultation methods. ${ }^{20}$

Hypotension was recorded in $52.9 \%$ while hypertension was documented in $1.2 \%$ of the subjects. Hypotension, being the commonest blood pressure abnormality in the current study may be related to the age at examination (up to six hours). Abnormal blood pressure in asphyxia has been linked to initial non-cerebral vasoconstriction, myocardial ischaemia and eventual heart failure. ${ }^{2}$

Respiratory distress was seen in $64.7 \%$ of asphyxiated neonates with HIE. This is within the range of $47.5 \%$ to $66.7 \%$ reported by other workers. ${ }^{10,21}$

Shock was present in $32.9 \%$ of the patients which was slightly lower than $45.0 \%$ to $48.3 \%$ reported by some authors in neonates with moderate to severe asphyx- 
ia. ${ }^{21,22}$ The lower incidence may be related to more newborn babies with mild to moderate asphyxia that constituted a large number $(88.2 \%)$ in the current study. In contrast, Rajakumar et $\mathrm{al}^{10}$ in India observed a lower incidence of $16.7 \%$ despite a similar study population. The higher incidence in the present study may be related to a larger sample size which was nearly thrice the number of new-born babies in the Indian study. Shock may be related to preferential shunting of blood, myocardial ischaemia, vasodilatation and blood loss. ${ }^{2}$ The presence of shock in asphyxiated new-borns may be associated with worse outcome and, as such, is an important clinical cardiovascular finding. ${ }^{23}$

Cardiac failure was present in $5.9 \%$ of the patients. This is comparable to $7.5 \%$ reported among asphyxiated neonates in India. ${ }^{21}$ It is, however, higher than figures of $1.6 \%$ and $2.5 \%$ reported by other workers. ${ }^{24}$ On the other hand, it is considerably lower than $36.7 \%$ observed by Zhu and Nie. ${ }^{25}$ The incidence reported in the current study may be related to the study population as $11.8 \%$ had severe HIE stage. Cardiac failure is most common in the late stage of HIE as the heart is preserved in the early phase of perinatal asphyxia. ${ }^{2}$

Systolic murmurs were present in $9.4 \%$ of the patients This is close to $10.0 \%$ reported by other workers. ${ }^{24} \mathrm{In}$ contrast, it is considerably lower than $20.0 \%$ reported by Rajakumaret al. ${ }^{10}$ Systolic murmurs often result from tricuspid insufficiency following an increase in the pulmonary pressure. ${ }^{23}$ It is important to note that systolic murmurs may be a normal finding in the new-born babies, as 21 per 1000 live births have been shown to have murmurs at birth without any significant cardiac abnormalities. ${ }^{26}$

Reduced peripheral perfusion was reported in about half of the patients, which is similar to $43.4 \%$ documented in an earlier study. ${ }^{25}$ Reduced peripheral perfusion occurs as a result of preferential shunting of blood so as to preserve the vital organs in the initial phase of asphyxia. ${ }^{2}$ Also, with prolonged asphyxia, heart failure ensues leading to poor circulation. ${ }^{2}$ Low oxygen saturation (SPO2 $\leq 94 \%$ ) was reported in $48.2 \%$ of the patients and may be related to poor peripheral perfusion. This is considerably lower than the incidence of $80.0 \%$ reported in the first 15 minute of life in another study. ${ }^{27}$ Since new-borns in the present study were examined at higher postnatal ages of up to six hours, they would be expected to have higher oxygen saturation. The increasing incidence of abnormal cardiovascular signs with
HIE severity in this study is consistent with findings by other authors. ${ }^{10,24}$ The documentation of pulse volume as the only parameter with an independent relationship with HIE severity in the present study is not out of place, as most of the significant parameters have a relationship with pulse volume.

None of the clinical signs was a significant predictor of mortality. It is difficult to compare our findings on the relationship between cardiovascular signs and stages of HIE because other studies did not subject these parameters to statistical tests.

\section{Conclusion}

The significant cardiovascular signs of clinical interest in HIE were poor peripheral perfusion, hypoxemia, small pulse volume, shock and heart failure. Pulse volume was the only parameter with independent relationship with HIE severity. None of the prarameters had any relationship with mortality. Identification of these signs may be a pointer to myocardial related ischaemic injury in asphyxiated neonates.

A large scale study among term asphyxiated babies with documentation of blood gases to assess the severity of metabolic acidosis is recommended. Electrocardiography and echocardiography might enhance our understanding of the cardiovascular status among the asphyxiated babies.

\section{Financial support/ Sponsorship}

Nil.

\section{Conflict of interest}

None.

\section{References}

1. Malcolm I, Vries L. Hypoxic-ischemic encephalopathy. In: Martin RJ, Fanaroff AA, Walsh MC, editors. Fanaroff and Martin's Neonatal Perinatal Medicine Disease of the Fetus and Infant. $8^{\text {th }}$ editio. Philadelphia: Mosby Elsevier, 2006. p. 113-20.

2. Tina AL, Neil AF. Resuscitation in the delivery room. In: Christine AG, Sherin UD, editors. Avery's Disease of the Newborn. $9^{\text {th }}$ ed. Philandephian: Saunder, Elsevia Inc, 2012. p. 328-34.

3. Cohn HE, Sacks EJ, Heyman MA, Abraham M Rudolph. Cardiovascular responses to hypoxemia and acidemia in fetal lambs. Am J Obstet Gynecol. 1974;120:81724. PubMed .

4. Pereira DN, Procianoy RS, Zatti H, Schlabendorff M. Manifestações clínicas em recém-nascidos a termo 
com diferentes graus de acidemia no sangue de cordão umbilical. J Pediatr (Rio J). 1999;75(3):195-200.

5. Kurinczuk JJ, White-Koning M, Badawi N. Epidemiology of neonatal encephalopathy and hypoxic-ischaemic encephalopathy. Early Hum Dev. 2010;86(6):329-38. PubMed

6. Lawn JE, Cousens S, Zupan J. 4Million neonataldeaths: When? Where? Why? Lancet. 2005;365(9462):891-900. PubMed

7. West B, Opara P. Perinatal asphyxia in a specialist hospital in Port Harcourt, Nigeria. Niger J Paediatr. 2013;40(3):206-10. PubMed

8. Miller SP, Weiss J, Barnwell A, Ferriero DM, Latal-Hajnal B, Ferrer-Rogers A, et al. Seizure-associated brain injury in term newborns with perinatal asphyxia. Neurology. 2002;58(4):542-8. PubMed

9. Sadoh WE, Eregie CO, Nwaneri DU, Sadoh AE. The diagnostic value of both troponin $\mathrm{T}$ and creatinine kinase isoenzyme (CK-MB) in detecting combined renal and myocardial injuries in asphyxiated infants. PLoS One. 2014;9(3):9-12. PubMed

10. Rajakumar PS, Vishnu Bhat B, Sridhar MG, Balachander J, Konar BC, Narayanan P, et al. Electrocardiographic and echocardiographic changes in perinatal asphyxia. Indian J Pediatr. 2009;76(3):261-4.

11. Sarnat HB, Sarnat MS. Neonatal Encephalopathy Following Fetal Distress: A Clinical and Electroencephalographic Study. Arch Neurol. 1976;33:696-705 PubMed .

12. Lubchenco LO, Hansman C, Dressler M, Boyd E. Intrauterine growth as estimated. Pediatrics. 1963;32(5):793-800. PubMed

13. Myung, K P. Physical examination. In: Myung, $\mathrm{k}$ P, Salamat M, Melton B, Scott P, Lopez L, Palacios M, editors. Paediatric Cardiology for Practitioners. Fifth. Philadelphia: Elsevier, Mossby; 2008. p. 9-35.

14. Sadoh WE, Ibhanesebhor SE. Oscillometric blood pressure reference values of African full-term neonates in their first days postpartum. Cardiovasc J Afr. 2009;20(6):344-8. PubMed

15. Lagunju IA, Omokhodion SI. Childhood heart failure in Ibadan. Vol. 22, West African Journal of Medicine. 2003. p. 42-5.

16. Michael A, Lynn M, David F. Principle of medical management. In: Michael A, Lynn M, David F, editors. Neonatal Cardiology. $2^{\text {nd }}$ ed. Newyork: McGraw-Hill Companies, Inc.; 2011. p. 217-8.
17. Hall RT, Hall FK, Daily DK. High-dose phenobarbital therapy in term newborn infants with severe perinatal asphyxia: A randomized, prospective study with three-year follow-up. Pediatrics. 1998;132:345-8 PubMed .

18. Abid A, Hakim IS, Javed C, Shayiq W, Arif HS, Rayees $\mathrm{AB}$, et al. The role of pulse oximetry in resuscitation of asphyxiated neonates. Eur J Gen Med. 2014;11(2):859. PubMed

19. Neligan GA, Oxon DM, Smith CA. The blood pressure of newborn infants in asphyxial states and in hyaline membrane disease. Pediatrics. 1960;26:735-44 PubMed .

20. Weaver MG, Park MK, Lee DH. Differences in blood pressure levels obtained by auscultatory and oscillometric methods. Am J Dis Child. 1990;144(8):911-4. 21. Agrawal J, Shah GS, Poudel P, Baral N, Agrawal A, Mishra OP. Electrocardiographic and enzymatic correlations with outcome in neonates with hypoxic-ischemic encephalopathy. Ital J Paediatr. 2012;38:1-5 PubMed . 22. Goel M, Poorva G, Yadav B. Assessment of myocardial function in birth asphyxia. Int $\mathrm{J}$ Med Res Rev. 2013;1(5):228-32. PubMed

23. Jay GP. Overview and initial management of delivery room resuscitation. In: Richard martin J, Avory F, Michele W, editors. Fanaroff and Martin's Neonatal Perinatal Medicine Disease of the Fetus and Infant. $10^{\text {th }}$ ed. Philadelphia: Elseviier Saunder, 2015. p. 460-4.

24. Pal P, Goel M. ECG changes in birth asphyxia and its correlation with Cardiac troponin - I. Int J Med Res Rev. 2015;3:400-3 PubMed .

25. Zhu R, Nie Z. Clinical study of the N-Terminal pro-brain natriuretic peptide in myocardial injury after neonatal asphyxia. Pediatr Neonatol [Internet]. 2016;57(2):133-9. Available from: http://dx.doi. org/10.1016/j.pedneo.2015.08.001

26. Arlettaz R, Archer N, Wilkinson AR. Natural history of innocent heart murmurs in newborn babies: controlled echocardiographic study. Arch Dis Child Fetal Neonatal Ed [Internet]. 1998;78(3):F166-70. Available from:http://www.pubmedcentral.nih.gov/articlerender.fcgi?artid=1720793\&tool=pmcentrez\&rendertype $=$ abstract

27. Rakesh R, Ramji S. Pulse oximetry in asphxiated newborns in the delivery room. Indian Peditrics. 2001;38:762-6 PubMed . 